\title{
Mechanism Underlying the Weight Loss and Complications of Roux-en-Y Gastric Bypass. Review
}

\author{
G Abdeen $^{1}$ - CW le Roux ${ }^{1,2,3}$ \\ Published online: 3 November 2015 \\ (C) The Author(s) 2015. This article is published with open access at Springerlink.com
}

\begin{abstract}
Various bariatric surgical procedures are effective at improving health in patients with obesity associated comorbidities, but the aim of this review is to specifically describe the mechanisms through which Roux-en-Y gastric bypass (RYGB) surgery enables weight loss for obese patients using observations from both human and animal studies. Perhaps most but not all clinicians would agree that the beneficial effects outweigh the harm of RYGB; however, the mechanisms for both the beneficial and deleterious (for example postprandial hypoglycaemia, vitamin deficiency and bone loss) effects are ill understood. The exaggerated release of the satiety gut hormones, such as GLP-1 and PYY, with their central and peripheral effects on food intake has given new insight into the physiological changes that happen after surgery. The initial enthusiasm after the discovery of the role of the gut hormones following RYGB may need to be tempered as the magnitude of the effects of these hormonal responses on weight loss may have been overestimated. The physiological changes after RYGB are unlikely to be due to a single hormone, or single mechanism, but most likely involve complex gut-brain signalling. Understanding the mechanisms involved with the beneficial and deleterious effects of RYGB will speed up the development of effective, cheaper and safer surgical and non-surgical treatments for obesity.
\end{abstract}

\section{G Abdeen}

Ghaliana@gmail.com

1 Investigative Science, Imperial College London, London, UK

2 Diabetes Complications Research Centre, Conway Institute, University College Dublin, Dublin, Ireland

3 Gastrosurgical Laboratory, University of Gothenburg, Gothenburg, Sweden
Keywords RYGB · Mechanism · Weight loss · Complications $\cdot$ Food preferences

\section{Introduction}

The Roux-en-Y gastric bypass (RYGB) includes a small gastric pouch $(15-30 \mathrm{~mL})$ on the lesser gastric curvature $[1,2]$ which is completely divided from the gastric remnant and then anastomosed to the jejunum (leaving an alimentary or Roux limb of typically $100-150 \mathrm{~cm}$ ). The size of the gastro-jejunal anastomosis is controversial as initially it was thought that an element of restriction may be helpful in slowing the progress of food from the oesophagus into the jejunum, but more recently the aim has been rapid transit of food into the jejunum to generate the gut signals to reduce meal size [3]. Bowel continuity is restored by an entero-entero anastomosis between the excluded biliopancreatic limb (BPL) and the alimentary limb. This anastomosis is usually performed 100$150 \mathrm{~cm}$ distal to the gastro-jejunostomy, although it has also been performed up to $250 \mathrm{~cm}$ distally in an attempt to create calorie malabsorption [1]. Usually, the BPL is approximately $50 \mathrm{~cm}$, but since other operations such as the biliopancreatic diversion or mini-gastric bypass with much longer BPL have greater reduction in insulin resistance, renewed interest in the length of the biliopancreatic limb BPL has developed [4].

Operative times vary between 45 and $90 \mathrm{~min}$ and the average hospital stay is 1-3 days, although same-day discharge following RYGB procedure have been successful [5]. Early complications, within 30 days after surgery, do occur in approximately $4 \%$ of patients and include bleeding, perforation or leakage, which need immediate surgical re-intervention [6]. Late complications such as significant abdominal pain, small bowel obstruction, anastomotic stenosis or marginal ulceration can occur in 15-20\% of patients after 30 days from 
surgery to over 10 years, and surgery or endoscopic therapy is often used for both diagnosis and/or treatment [7].

Even though RYGB does not treat some of the aetiological factors of morbid obesity, such as the obesogenic environment we live in, it does successfully result in 20-30\% long term, over 2 years of weight loss and maintenance [8-10], in addition to an improvement or remission of many obesity-related co-morbidities [11-15] such as hypertension, type 2 diabetes mellitus, obstructive sleep apnoea and musculoskeletal pain. Approximately $40 \%$ of obese patients with type 2 diabetes go into remission within days or weeks after RYGB [16].

The RYGB is the best studied procedure regarding underlying mechanisms. The aim of this review is to describe the mechanisms through which RYGB surgery enables weight loss for obese patients and helps in understanding its complications by using observations from both human and animal studies.

\section{Food Intake}

\section{Research Studies}

\section{Hunger and Fullness}

Lifestyle changes with a lower calorie diet can be effective at initiating weight loss; however, most of the results from randomised controlled trials (RCT) are disappointing regarding long-term weight loss maintenance $[17,18]$. Approximately $70-80 \%$ of patients fail to maintain their initial lifestyle-induced weight loss thought to be due to physiologically compensatory responses that defend the previous weight 'set point' [19]. Whilst on a long-term low-calorie diet, patients usually report an increase in hunger, a decrease in satiety and pre-occupation with energy-dense fatty and sweet food [20, 21]. This may be part of a normal physiological response and not due to lack of motivation.

Reduced calorie intake after RYGB is usually a consequence of significantly smaller meal sizes, and reduced calorie content of food eaten [22] compensated only partially by increased meal frequency [23]. Enhanced satiety is the dominant contributing factor [24]. A dramatic decrease in daily energy intake, $600-700 \mathrm{kcal}[22,25]$, during the first month postsurgery increases to $1000-1800 \mathrm{kcal}$ during the first year [22, 26-32]. An average reduction of $1800 \mathrm{kcal}$ per day from pre-operative intake can be sustained for several years [32, 33]. Protein intake during the first year after surgery is often lower than recommended at $0.5 \mathrm{~g} / \mathrm{kg}$, rather than the recommendation of at least $1.5 \mathrm{~g} / \mathrm{kg} /$ day $[27,34]$. The mechanisms are unclear, but may be due to temporary intolerance of higher protein diet and dairy foods [22, 25, 27, 35-37]. Relative intake of fat and carbohydrates decrease during the first year post-surgery, but return to the baseline after 1 year [22], although the contribution of high and low glycaemic index carbohydrates may change. Many patients reduce their intake of high glycaemic index carbohydrates and increase their intake of lower glycaemic index carbohydrates. Changes in behaviour associated with eating after RYGB were reported in the 1970s using structured interviews that suggested that patients reached satiety more quickly, with the most common reason given as a 'lack of desire' for food [38].

\section{Potential Mediators}

\section{Increased Transit of Food into the Midgut} Through the Gastric Pouch

Whether the size of the gastric pouch and stoma in RYGB surgery affects food intake and body weight is contested. It remains controversial in both the human and animal literature whether a larger gastric pouch and stoma causes less weight loss [39-43]. The stoma becomes more 'compliant' with time, allowing food to transit more easily from the pouch into the alimentary limb, but may also result in food being 'stored' in the pouch and not emptying rapidly enough. Thus, the initial diameter of the anastomosis may not affect weight loss in the long term [44]. To study a RYGB technique that created a very small pouch, a high-pressure manometer was used, but a large stoma demonstrated that the pressure in the pouch (immediately proximal to the gastroenteral anastomosis) was lower than in the alimentary limb [45]. This suggests there was no restriction at the level of the stoma because of the absence of a high-pressure zone proximal to the pouch. Insertion of a gastric balloon into the alimentary limb and inflation of the balloon to a pressure of $20 \mathrm{~cm}$ water demonstrated that patients with the highest pressure generated by the alimentary limb had the smallest meal volume during an ad libitum meal. In contrast, those with the lowest pressure in the alimentary limb took longer to terminate their meal. Mechanoreceptors within the alimentary limb may be important determinants of meal size if food rapidly transits through the pouch to reach the alimentary limb in a less digested state than usual. The component that determines caloric intake may be the alimentary limb and not the pouch size or stoma diameter.

\section{Hormonal}

RYGB alters endogenous gut hormone responses to a meal. Glucagon-like peptide-1 (GLP-1), peptide YY (PYY) and ghrelin have been the best studied candidates in the context of reduced food intake and sustained weight loss after RYGB. GLP-1 and PYY responses to mixed meals or oral glucose have been at the centre of interest of several studies investigating patients 6 weeks to 10 years after RYGB [46-51]. Significantly elevated responses are seen in GLP-1 and PYY as early as 2 days after RYGB [52] and may remain elevated 
for more than a decade after RYGB [53]. Patients who lost the most weight after RYGB also had the highest levels of these postprandial satiety gut hormones $[54,55]$. Blocking the release of these hormones in humans and rats with octreotide increased food intake after RYGB, but not after adjustable gastric banding (AGB) surgery in humans [51] or sham operations in rats [56].

Mechanistic studies in rodents have suggested the physiological significance of PYY because weight loss in PYYknockout mice after a RYGB variant was lower than in wild-type mice [57]. Exogenous PYY specific antibodies also increased food intake in rats after bypass type procedures [51]. Physiologically, PYY has been shown to delay gut transit time, but probably does not increase energy expenditure in human [58]. GLP-1 responses are very similar to those of PYY after RYGB, but have additionally been linked with increases in insulin secretion $[59,60]$. Postprandial responses of GLP-1 before surgery do not correlate with change in weight loss after surgery, suggesting that pre-operative gut hormone responses are not prognostic [61]. Enhanced GLP-1 signalling on its own is also not sufficient to reduce body weight after RYGB, suggesting that it is multiple gut hormone responses that mediate the increased satiation after a meal [62].

Reduced ghrelin was the first proposed hormonal mechanism to explain weight loss after RYGB. At first, ghrelin levels were thought to be lower compared to diet-induced weight loss which increased ghrelin in a control group of subjects [63]. It was postulated that this decrease was partially responsible for reduced hunger after RYGB. Subsequent studies in patients after RYGB were more controversial reporting a reduction in fasting and postprandial ghrelin levels [50, 64-70], no alteration in fasting and postprandial levels [51, $52,71-79]$ and a rise in fasting ghrelin levels [80-84]. Considering all the data and variability, it is likely that RYGB results in a comparative ghrelin deficiency considering that ghrelin normally increases after diet-induced weight loss, but the magnitude of this contribution is unclear $[85,86]$.

\section{Neural}

The vagal afferent fibres in the gastric and proximal small bowel mucosa are known to be sensitive to mechanical stretch in order to detect the volume of ingested food [87]. The vagus nerve with both the ventral and dorsal gastric branches on the large gastric remnant is transected during the formation of the gastric pouch. The vagal fibres to the gastric pouch are thus intact, and these could mediate satiety as food passes through the pouch. The vagal denervation more distally may attenuate signalling. Taken together, this may play a role in satiation [88]. Visceral sensory information from the gut is communicated centrally using the afferent (sensory) vagus nerve signalling to the nucleus of the tractus solitarius (NTS). Here, visceral sensory information and hormonal and metabolic inputs are integrated together with neuronal inputs from other brainstem areas [89] and may well be the most important way in which RYGB signals to the brain. Transmission of these signals involving the gut hormones such as ghrelin may be impaired after vagotomy [90]. RYGB appears to have the potential to alter neural responses [91] to reduce hedonic behaviour associated with eating highly palatable and caloriedense foods. These changes in reward value of food may alter the amount of food consumed [38, 92-94].

\section{Change in Bile Acids}

Bile acids are agonists for the cell-membrane G proteincoupled receptors, TGR5, which in turn enhances the release of GLP-1 and PYY. Bile acids also bind the farnesoid X receptor (FXR) [95]. The anatomical changes after RYGB result in bile progressing down the biliopancreatic limb to the distal $\mathrm{L}$ cells without mixing with food. As a result, the availability of undiluted bile acids in the distal intestine may enhance stimulation of TGR 5 receptors on L cells [96]. Serum bile acid concentration is raised after RYGB [97] and is associated with increased energy expenditure possibly through signalling via the cyclic adenosine monophosphate cAMP-dependent thyroid hormone triggering enzyme type 2 iodothyronine deiodinase [98]. Fibroblast growth factor (FGF) 19 is increased and binds to fibroblast growth factor receptor (FGFR4) activating fibroblast growth factor receptor c-kit (FGRR1c) in the presence of co-receptor $\beta$ Klotho [99]. The result is increased protein synthesis in the liver [100]. FGF19 also plays a role in enhanced mitochondria activity [100]. Activation of the FXR receptor may facilitate the effects of bile acids on energy homeostasis through FGF19 that is released from ileal enterocytes which can lead to increases in metabolic rate and decreases in adiposity [101, 102].

Bile acids, after a mixed test meal in human subjects, was positively correlated with circulating GLP-1 and PYY, but negatively correlated with ghrelin [103]. Pournaras et al. have demonstrated that total plasma bile acids are elevated after RYGB [104] and suggested that they may be partly responsible for the intestinal hypertrophy, anorexigenic hormone secretion and alterations in gut microbiota [105].

\section{Change in Gut Microbiota}

Obesity is associated with low-grade inflammation, increased Firmicutes and decreased Bacteroidetes in animals [106] and humans [107-109]. Intestinal microbiota has also been shown to utilise energy from food and thus increase the host's energyharvesting capacity [110]. Proteobacteria (gammaproteobacteria) has been shown to increase after RYGB in humans [111] with the major contributor being Enterobacter hormaechei. The significant improvement of weight, inflammation and metabolic status after surgery was 
associated with increased bacterial variety. An association was observed between adipose tissue gene expression and bacterial genes at baseline with a 10-fold increase 3 months after surgery, and this may suggest a restored crosstalk between both the gut microbiota and the host [112].

After RYGB, acidity was reduced in the alimentary limb leading to a decrease of hydrochloric acid flux in the gut, while bile acids were increased in the biliopancreatic limb. Bacteroidetes growth was attenuated at lower $\mathrm{pH}$, whereas Escherichia coli increased at a higher $\mathrm{pH}$. Gut microbiota quickly adapt in a 'starvation-like state' created by RYGB and rapidly and sustainably increase. Changes in microbiota in mice after RYGB were independent of weight alteration and caloric restriction [113]. Transfer of the gut microbiota from RYGB-treated mice to non-operated, germ-free mice resulted in weight loss and reduced fat mass in the recipient animals. The altered microbial production of short-chain fatty acids that increases may partly be an explanation [113]. Although RYGB did not change gut microbiota from the 'obese state' to the 'lean state', it did create a 'third state' which on balance appear to be associated with many of the beneficial characteristics of RYGB.

\section{Food Preferences}

\section{Observations}

Weight gain has been linked to a preference for both sweet and/or high-fat foods [114, 115], which may partly explain why obese people regain body weight frequently after 'dieting' [116, 117]. The common view summarised earlier by Pangborn and Simone is: "In the mind of a normal person, sugar and sweets are 'fattening' and most overweight people have a 'sweet tooth"' [118]. Hedonism associated with palatable foods is considered a significant factor which increases the prevalence of obesity. A motivational factor that is referred to as 'hedonic hunger' [119] may be a trigger for overeating [120].

Patients after RYGB tend to increase the intake of fruit and vegetables as well as low-fat food [121, 122]. The dumping syndrome was thought to induce these changes in food preference [123], as initially it was considered as a useful characteristic of the RYGB to 'teach' patients to avoid calorie-dense foods and thus consume fewer calories [124]. However, patients after RYGB appear to make healthier food choices and adopt a more balanced diet (even when they do not experience dumping) [121, 125] and have considerable reduction in energy intake (EI) and energy density. A comparison on food groups was done for a group of patients after RYGB and total number of servings from fat, grains and sweetened beverages was reduced and remained reduced in the longer term. However, meats, dairy products, fruits and sweets were reduced in the short term, but then returned to baseline by 12 months [22]. When energy intake was reduced to $1300 \mathrm{kcal}, 60$ and $25 \%$ of patients, respectively, were consuming less than one serving per day from both fruits and vegetables. Whole grains intake increased from 25 to $40 \%$ within the first 3 months, but then returned to baseline at 12 months [22]. The association between reduced diet energy density and weight loss is controversial as some studies describe no association [126], while others show that shifts in food preferences are partially responsible for the decreased calorie intake and weight loss after RYGB [127].

RYGB in humans appears to alter taste through unconditional and conditional mechanisms [24, 128-130] leading to the concept of 'behaviour surgery' [123]. In 1987, Sugerman et al. reported that 'sweet-eaters' did particularly well after RYGB [131, 132]. Some of the initial findings were confounded by intolerance to sweets related to symptoms of the dumping syndrome [38, 131-133]. Conditioned taste aversion may thus be a factor in some patients. These initial assumptions resulted in many clinicians thinking that the RYGB works by 'punishing' the 'poor behaviours' of obese patients. The notion that RYGB becomes an external enforcer that goes against the free will of the patient has led to some authors questioning the morality of RYGB as a tool that changes patients' behaviour against patients' natural wishes [134]. This misconception may have reduced the wider acceptance of RYGB as a valid physiological treatment for the pathology that results in obesity. Classical conditioned food aversion is, however, an unlikely explanation as most patients with severe dumping still report that they like the taste of sweet foods, but that they have learned to consume only small quantities that do not cause negative visceral symptoms or consume sweets at night before bedtime, suggesting a conditioned food avoidance to be a more likely explanation. Distinguishing between the terms is important because avoidance implies that the palatability of sweet or fat did not change when small quantities are consumed, but that the subject 'learns' to stop consuming the food sooner (earlier avoidance) because large quantities may have negative visceral consequences [135-137].

\section{Mediators}

RYGB could be exerting its effects on food selection and preference through any one of the taste function domains important in normal physiology such as sensory-discriminative (stimulus identification), hedonic (ingestive motivation) and physiological (digestive preparation) [138, 139]. Affective responses to taste stimuli, which can be considered an example of ingestive motivation, can be both conditioned and unconditioned. It remains controversial which of these three domains are involved and what their interactions are to determine food preferences after RYGB surgery. For example, 
RYGB could have effects directly on the central gustatory pathways related with feeding and reward through gut hormonal mediators. Alternatively, changes in the sensory signals could alter the intensity or the quality of tastants, but also lead to an unconditioned change in palatability. If RYGB causes visceral malaise after ingestion of fat, then it is possible that the palatability of fat could alter through a process of learning (conditioned response) [140].

Although there are suggestions in animal models that the hedonic properties of sweet and fat stimuli may change after RYGB [23, 140-144], less work has been done in humans. Miras et al. using the progressive ratio task showed that RYGB resulted in the selective decrease of the reward value of a sweet and fat tastant, but not vegetables [145]. Further support comes from studies of brain reward cognitive systems linked to eating behaviour as studied by functional MRI (fMRI), where brain hedonic responses to caloriedense food are lower after RYGB compared to patients who have lost similar amounts of weight after adjustable gastric banding [128].

\section{Energy Expenditure}

According to the laws of thermodynamics, energy that enters a system (energy intake) must either be stored (body energy gain) or be used (activity, heat or faecal energy loss). Energy expenditure (EE) is usually decreased during food restriction, a phenomenon known as the 'starvation response' [146]. Weight loss in rodent models of RYGB is associated with preservation of lean body mass and increased EE [146]. Humans have decreased basal metabolic rate, but increased meal-induced thermogenesis after RYGB [32, 122, 147-153]. Evidence is now also emerging to suggest that the metabolic rate of the small bowel is increased after RYGB with more carbohydrate consumption which may explain the changes observed in respiratory quotient after these operations [154]. Reduced resting energy expenditure (REE) or basal metabolic rate after RYGB [122, 147, 155-157] may be attenuated due to relative lean mass preservation. Patients who regain the weight they lost 2 years after RYGB have lower REE [149], suggesting that elevating REE after RYGB may enhance weight loss. Physical activity may further help increase activity-related EE and also preserve lean mass, and therefore REE, after RYGB [158].

\section{Calorie Malabsorption}

Several bariatric operations were designed to result in malabsorption of calories [159]. The exclusion of the approximately $10 \%$ of the bowel ( $50 \mathrm{~cm}$ of BPL) after RYGB is unlikely to result in calorie malabsorption usually during other small bowel resections. Moreover, the exaggerated gut hormone responses which reduce gut transit have a net result of RYGB not altering oro-caecal transit time or functional enterocyte mass [16]. RYGB may, however, impair pancreatic exocrine function which could contribute to a small amount of fat malabsorption, the magnitude of which is probably too small to contribute substantially to weight loss [160-162].

\section{Mechanisms of Complications}

The rise in the number of RYGB procedures [163] has also increased the absolute number of complications associated with this procedure even though the percentage of patients with complications has reduced due to better surgical experience [164].

Postprandial hypoglycaemia, even in patients who never had type 2 diabetes, can occur several hours after a meal and is distinct from early dumping syndrome which occurs within minutes after eating $[165,166]$. Early dumping is an outcome of rapid emptying of food into the jejunum due to the lack of a pylorus presumably causing neural activation in the proximal alimentary limb [167]. Late dumping, or 'postprandial hypoglycaemia', happens $1-3 \mathrm{~h}$ after ingesting a meal and is a result of the exaggerated insulin response to high glycaemic index carbohydrates in the meal. The proposed mechanisms involve increased $\beta$-cell mass and improved $\beta$-cell function and non- $\beta$-cell mechanisms, which may include a lack of ghrelin (a counter-regulatory measure to hypoglycaemia) $[63,168]$. In addition, the sustained weight loss can reduce insulin resistance which renders the previous insulin responses needed pre-surgery to suddenly become excessive. The aetiology of hypoglycaemia is likely to be different for individual patients and is also probably a mixture of the anatomic, hormonal and metabolic changes after RYGB [169]. Although treatment of this complication can be difficult, pancreatectomies are no longer advised [170], but rather a multimodal medical approach is favoured [171].

\section{Unexplained Abdominal Pain}

Up to $10 \%$ of the patients complain of unexplained chronic abdominal pain which can be difficult for both the treating clinician and patient to acknowledge [172, 173]. Mild abdominal pain is reported by up to $95 \%$ of patients at some point after RYGB [172, 174-176]. Symptom severity fluctuates between vague discomfort and severe colicky pain [177]. Vomiting and nausea, especially if prolonged, are symptoms of pathology and are not part of the normal postoperative course after RYGB; nonetheless, up to $80 \%$ of patients report the symptoms at some point after surgery $[172,174]$. Abdominal pain may be recurrent, and it should be remembered that internal hernias may spontaneously reduce causing 
intermittent pain. Early investigation when acute symptoms of abdominal pain first presents is mandatory due to the risk of obstruction, volvulus and ischaemia of the herniated bowel $[172,178]$. Cross-sectional imaging is often unhelpful and the use of laparoscopy is frequently required for diagnosis. Management protocols for chronic unexplained abdominal pain are not clearly defined, but the jejunal-jejunal anastomosis is currently receiving more attention as a possible cause for these chronic problems.

\section{Anastomotic Stenosis}

With the circular stapler technique, this can be a common complication with a reported incidence of up to $27 \%$ and a recurrence rate of up to $33 \%$ [179]. Usually dysphagia occurs within 6 months after surgery. Endoscopy can often be used both as a diagnostic but also an intervention tool.

\section{Vitamin Deficiencies: Iron, Vitamin B12, Folic Acid, Vitamin D and Calcium}

Iron deficiency occurs in up to $49 \%$ of patients after RYGB [180]. Reduced acid production in the small stomach pouch decreases iron absorption [181]. For iron to be absorbed, the ferric iron in foods has to be reduced to the ferrous state, but because hydrochloric acid is lower after RYGB, this process is attenuated [182]. Reduced intake of iron-rich foods after RYGB such as red meat may also contribute [183, 184].

In the stomach, both pepsin and hydrochloric acid are required for absorption of vitamin B12. Deficiencies of vitamin B12 occur in up to $70 \%$ of patients after RYGB [184-186] because achlorhydria prevents vitamin B12 separation from foods due to reduced ingestion of meat and insufficient secretion of intrinsic factor after surgery [182].

Folic acid deficiency affects up to $35 \%$ of patients after RYGB. Folate absorption is enabled by hydrochloric acid with absorption in the proximal third of the small bowel most important [186]. Vitamin B12 also acts as a coenzyme in converting methyltetrahydrofolate to tetrahydrofolate. Thus, folate deficiency might result from achlorhydria, bypassing of the proximal small bowel, vitamin B12 deficiency and/or decreased folate ingestion [184-187].

Hypocalcaemia occurs in up to $10 \%$ and low serum 25 hydroxy vitamin D levels in up to half of RYGB patients [188]. Nevertheless, most obese patients had significantly lower basal 25-hydroxyl vitamin D concentrations and higher parathyroid hormone concentrations as compared to age-matched lean controls [189]. Deficiencies may occur because calcium is typically absorbed in the proximal small bowel which is bypassed after RYGB. Intolerances can develop to calcium-rich sources such as milk especially if the fat content is high. Calcium can be released from bone as evident from the increased bone turnover and subsequent reduced bone mass after RYGB [190, 191]. The higher bone turnover in the RYGB patients could be partly due to the weight loss in these patients [192], but animal studies suggest that bone loss exceeds what would be expected from weight loss alone [193].

\section{Loss of Bone Density}

Many patients with obesity have very healthy bone density before surgery due to long-term excessive weight bearing. This may be protective and partly explains the controversy of why the loss of bone density after RYGB does not cause more bone fractures [194, 195] even if the risk for fracturing may be increased. Multiple mechanisms may contribute to RYGB reducing bone density, including physiologically reduced mechanical load related to weight loss after surgery, hyperparathyroidism due to insufficient calcium consumption or reduced intestinal calcium and vitamin $\mathrm{D}$ absorption. Humoral factors from adipose tissue (oestradiol, leptin, adiponectin), pancreas (e.g. insulin, amylin) or the gut (ghrelin, glucagon-like peptide-2, glucose-dependent insulinotropic peptide) may also play a role $[196,197]$ by connecting a web of consistent regulatory pathways [196].

\section{Kidney Stones}

Hyperoxaluria is common after RYGB, but the incidence of renal calculi is much lower than after jejunal-ileal bypass (JIB) [198-200]. Comparison with the JIB is important because the incidence as well as the potential mechanisms may be different after RYGB. The lithogenic effects after RYGB may stem from reduced calcium binding to oxalate in the intestinal lumen. The excess oxalate is then cleared by the kidneys resulting in hyperoxaluria and calcium oxalate nephrolithiasis. Almost $21 \%$ of patients after JIB, which causes significant malabsorption, developed kidney stones 5 years after surgery [201], but the incidence of kidney stones after RYGB appears to depend on a combination of other factors such as hydration status and urine volume [200]. Patients in high stone-forming areas of the world have increased number of stones while those in low stone-forming countries may have an incidence similar to the background population [202]. Thus, RYGB alone is not enough to cause kidney stones, but it does potentiate other predisposing factors.

\section{Conclusion}

RYGB confers both benefits and complications, the mechanisms of which are still only partially understood. Most, but not all, clinicians would agree that the beneficial effects outweigh the harm that may be caused [203]. The exaggerated release of the satiety gut hormones with their central and 
peripheral effects on glycaemia and food intake [52, 75, 204] has given new insight into the physiological changes that take place after surgery. The initial enthusiasm after the discovery of the role of the gut hormones may need to be tempered as the magnitude of the effects of these gut hormones on weight loss may have been overestimated. The physiological changes after RYGB are unlikely to be due to a single hormone, or single mechanism, but are more likely to additionally involve complex gut-brain nutrient and neural signalling [205, 206]. Understanding these mechanisms will speed up the development of more effective and safer surgical and non-surgical treatments for obesity.

All studies that are mentioned in the review adhered to the expected high level ethical considerations and were approved by the appropriate institutional review board.

Open Access This article is distributed under the terms of the Creative Commons Attribution 4.0 International License (http:// creativecommons.org/licenses/by/4.0/), which permits unrestricted use, distribution, and reproduction in any medium, provided you give appropriate credit to the original author(s) and the source, provide a link to the Creative Commons license, and indicate if changes were made.

\section{Reference}

1. Rubino F, Schauer PR, Kaplan LM, Cummings DE. Metabolic surgery to treat type 2 diabetes: clinical outcomes and mechanisms of action. Annu Rev Med. 2010;61:393-411.

2. Pories WJ. Bariatric surgery: risks and rewards. J Clin Endocrinol Metab. 2008;93:s89-96.

3. Laurenius A, Larsson I, Bueter M, et al. Changes in eating behaviour and meal pattern following Roux-en-Y gastric bypass. Int J Obes. 2012;36:348-55.

4. Nora M, Guimarães M, Almeida R, et al. Metabolic laparoscopic gastric bypass for obese patients with type 2 diabetes. Obes Surg. 2011;21:1643-9.

5. McCarty TM, Arnold DT, Lamont JP, Fisher TL, Kuhn JA. Optimizing outcomes in bariatric surgery: outpatient laparoscopic gastric bypass. Ann Surg. 2005;242:494.

6. Sjostrom L, Lindroos AK, Peltonen M, et al. Lifestyle, diabetes, and cardiovascular risk factors 10 years after bariatric surgery. $\mathrm{N}$ Engl J Med. 2004;351:2683-93.

7. Franco J, Ruiz P, Palermo M, Gagner M. A review of studies comparing three laparoscopic procedures in bariatric surgery: sleeve gastrectomy, Roux-en-Y gastric bypass and adjustable gastric banding. OBES SURG. 2011;21:1458-68.

8. Wing RR, Phelan S. Long-term weight loss maintenance. Am J Clin Nutr. 2005;82:222S-5S.

9. Cooper Z, Doll HA, Hawker DM, et al. Testing a new cognitive behavioural treatment for obesity: a randomized controlled trial with three-year follow-up. Behav Res Ther. 2010;48:706-13.

10. Olbers T, Gronowitz E, Werling M, et al. Two-year outcome of laparoscopic Roux-en-Y gastric bypass in adolescents with severe obesity: results from a Swedish Nationwide Study (AMOS). Int J Obes. 2012;36:1388-95.

11. Boza C, Gamboa C, Awruch D, Perez G, Escalona A, Ibañez L, et al. Laparoscopic Roux-en-Y gastric bypass versus laparoscopic adjustable gastric banding: five years of follow-up. Surg Obes Relat Dis. 2010;6:470-5.

12. Wong SK, Kong AP, Mui WL, et al. Laparoscopic bariatric surgery: a five-year review. Hong Kong Med J. 2009;15(2):100-9.

13. Kim TH, Daud A, Ude AO, et al. Early U.S. outcomes of laparoscopic gastric bypass versus laparoscopic adjustable silicone gastric banding for morbid obesity. Surg Endosc. 2006;20:202-9.

14. Lakdawala M, Bhasker A, Mulchandani D, Goel S, Jain S. Comparison between the results of laparoscopic sleeve gastrectomy and laparoscopic Roux-en-Y gastric bypass in the Indian population: a retrospective 1-year study. Obes Surg. 2010;20:1-6.

15. Weber M, Müller MK, Bucher T, et al. Laparoscopic gastric bypass is superior to laparoscopic gastric banding for treatment of morbid obesity. Ann Surg. 2004;240:975-82.

16. Pournaras DJ, Osborne A, Hawkins SC, et al. Remission of type 2 diabetes after gastric bypass and banding: mechanisms and 2 year outcomes. Ann Surg. 2010;252:966-71.

17. Sorensen TIA. Weight loss causes increased mortality: pros. Obes Rev. 2003;4:3-7.

18. Gerstein HC. Do lifestyle changes reduce serious outcomes in diabetes? N Engl J Med. 2013;369:189-90.

19. Maclean PS, Bergouignan A, Cornier MA, Jackman MR. Biology's response to dieting: the impetus for weight regain. Am J Physiol Regul Integr Comp Physiol. 2011;301:R581-600.

20. Sumithran P, Prendergast LA, Delbridge E, et al. Long-term persistence of hormonal adaptations to weight loss. N Engl J Med. 2011;365:1597-604.

21. Hofmann W, van Koningsbruggen GM, Stroebe W, Ramanathan $\mathrm{S}$, Aarts H. As pleasure unfolds. Hedonic responses to tempting food. Psychol Sci. 2010;21:1863-70.

22. Miller GD, Norris A, Fernandez A. Changes in nutrients and food groups intake following laparoscopic Roux-en-Y gastric bypass (RYGB). Obes Surg. 2014;24(11):1926-32. 1-7.

23. Zheng H, Shin AC, Lenard NR, et al. Meal patterns, satiety, and food choice in a rat model of Roux-en-Y gastric bypass surgery. Am J Physiol Regul Integr Comp Physiol. 2009;297:R1273-82.

24. Miras AD, Le Roux CW. Mechanisms underlying weight loss after bariatric surgery. Nat Rev Gastroenterol Hepatol. 2013;10: 575-84.

25. Xanthakos SA. Nutritional deficiencies in obesity and after bariatric surgery. Pediatr Clin N Am. 2009;56:1105-21.

26. Lindroos AK, Lissner L, Sjostrom L. Weight change in relation to intake of sugar and sweet foods before and after weight reducing gastric surgery. Int J Obes Relat Metab Dis J Int Assoc Study Obes. 1996;20:634 43.

27. Moize V, Geliebter A, Gluck ME, et al. Obese patients have inadequate protein intake related to protein intolerance up to 1 year following Roux-en-Y gastric bypass. Obes Surg. 2003;13:23-8.

28. Bobbioni-Harsch E, Huber O, Morel PH, et al. Factors influencing energy intake and body weight loss after gastric bypass. Eur J Clin Nutr. 2002;56:551-6.

29. Brolin RL, Robertson LB, Kenler HA, Cody RP. Weight loss and dietary intake after vertical banded gastroplasty and Roux-en-Y gastric bypass. Ann Surg. 1994;220:782.

30. Naslund I, Jarnmark I, Andersson H. Dietary intake before and after gastric bypass and gastroplasty for morbid obesity in women. Int J Obes. 1987;12:503-13.

31. Coughlin K, Bell RM, Bivins BA, Wrobel S, Griffen WO. Preoperative and postoperative assessment of nutrient intakes in patients who have undergone gastric bypass surgery. Arch Surg. 1983;118:813-6.

32. Flancbaum L, Choban P, Bradley LR, BURGE JC. Changes in measured resting energy expenditure after Roux-en- $Y$ gastric bypass for clinically severe obesity. Surgery. 1997;122:943-9. 
33. Warde-Kamar J, Rogers M, Flancbaum L, Laferrère B. Calorie intake and meal patterns up to 4 years after Roux-en-Y gastric bypass surgery. Obes Surg. 2004;14:1070-9.

34. Bavaresco M, Paganini S, Lima TP, et al. Nutritional course of patients submitted to bariatric surgery. Obes Surg. 2010;20: 716-21.

35. Schinkel ER, Pettine SM, Adams E, Harris M. Impact of varying levels of protein intake on protein status indicators after gastric bypass in patients with multiple complications requiring nutritional support. Obes Surg. 2006;16:24-30.

36. Westerterp-Plantenga MS, Nieuwenhuizen A, Tome D, Soenen S, Westerterp KR. Dietary protein, weight loss, and weight maintenance. Annu Rev Nutr. 2009;29:21-41.

37. Heber D, Greenway FL, Kaplan LM, Livingston E, Salvador J, Still C. Endocrine and nutritional management of the postbariatric surgery patient: an Endocrine Society Clinical Practice Guideline. J Clin Endocrinol Metabol. 2010;95:4823-43.

38. Halmi KA, Mason E, Falk JR, Stunkard A. Appetitive behavior after gastric bypass for obesity. Int J Obes. 1981;5:457-64.

39. Heneghan HM, Yimcharoen P, Brethauer SA, Kroh M, Chand B. Influence of pouch and stoma size on weight loss after gastric bypass. Surg Obes Relat Dis. 2012;8:408-15.

40. Bueter M, Löwenstein C, Ashrafian $\mathrm{H}$, et al. Vagal sparing surgical technique but not stoma size affects body weight loss in rodent model of gastric bypass. Obes Surg. 2010;20:616-22.

41. Campos GM, Rabl C, Mulligan K. Factors associated with weight loss after gastric bypass. Arch Surg. 2008;143:877-84.

42. Topart P, Becouarn G, Ritz P. Pouch size after gastric bypass does not correlate with weight loss outcome. Obes Surg. 2011;21: $1350-4$.

43. Madan A, Tichansky D, Phillips J. Does pouch size matter? Obes Surg. 2007; 17:317-20.

44. Gould J, Garren M, Boll V, Starling J. The impact of circular stapler diameter on the incidence of gastrojejunostomy stenosis and weight loss following laparoscopic Roux-en-Y gastric bypass. Surg Endosc. 2006;20:1017-20.

45. Fandriks L. The role of the smaller stomach. 31-8-2011. Postgraduate course B, XVI World Congress of the International Federation for the Surgery of Obesity and Metabolic Disorders, Hamburg, Germany. Ref Type: Report

46. Laferrere B, Heshka S, Wang K, et al. Incretin levels and effect are markedly enhanced 1 month after Roux-en-Y gastric bypass surgery in obese patients with type 2 diabetes. Diabetes Care. 2007;30:1709-16.

47. Laferrere B, Teixeira J, McGinty J, et al. Effect of weight loss by gastric bypass surgery versus hypocaloric diet on glucose and incretin levels in patients with type 2 diabetes. J Clin Endocrinol Metab. 2008;93:2479-85.

48. Morinigo R, Moize V, Musri M, et al. Glucagon-like peptide-1, peptide $\mathrm{YY}$, hunger, and satiety after gastric bypass surgery in morbidly obese subjects. J Clin Endocrinol Metabol. 2006;91: 1735-40.

49. Korner J, Inabnet W, Conwell IM, et al. Differential effects of gastric bypass and banding on circulating gut hormone and leptin levels. Obesity (Silver Spring). 2006;14:1553-61.

50. Rodieux F, Giusti V, D'Alessio DA, Suter M, Tappy L. Effects of gastric bypass and gastric banding on glucose kinetics and gut hormone release. Obesity (Silver Spring). 2008;16:298-305.

51. le Roux CW, Aylwin SJ, Batterham RL, et al. Gut hormone profiles following bariatric surgery favor an anorectic state, facilitate weight loss, and improve metabolic parameters. Ann Surg. 2006;243:108-14.

52. Le Roux CW, Welbourn R, Werling M, et al. Gut hormones as mediators of appetite and weight loss after Roux-en-Y gastric bypass. Ann Surg. 2007;246:780-5.
53. Dar MS, Chapman III WH, Pender JR, et al. GLP-1 response to a mixed meal: what happens 10 years after Roux-en-Y gastric bypass (RYGB)? Obes Surg. 2012;22:1077-83.

54. Meguid MM, Glade MJ, Middleton FA. Weight regain after Rouxen-Y: a significant $20 \%$ complication related to PYY. Nutrition. 2008;24:832-42.

55. Dirksen C, Jorgensen NB, Bojsen-Moller KN, et al. Gut hormones, early dumping and resting energy expenditure in patients with good and poor weight loss response after Roux-en-Y gastric bypass. Int J Obes. 2013;37(11):1452-9.

56. Batterham RL, Cohen MA, Ellis SM, et al. Inhibition of food intake in obese subjects by peptide YY3-36. N Engl J Med. 2003;349:941-8.

57. Chandarana K, Gelegen C, Karra E, et al. Diet and gastrointestinal bypass-induced weight loss: the roles of ghrelin and peptide YY. Diabetes. 2011;60:810-8.

58. Sloth B, Holst JJ, Flint A, Gregersen NT, Astrup A. Effects of PYY1-36 and PYY3-36 on appetite, energy intake, energy expenditure, glucose and fat metabolism in obese and lean subjects. Am J Physiol Endocrinol Metabol. 2007;292:E1062-8.

59. Troy S, Soty M, Ribeiro L, et al. Intestinal gluconeogenesis is a key factor for early metabolic changes after gastric bypass but not after gastric lap-band in mice. Cell Metab. 2008;8:201-11.

60. Peterli R, Wolnerhanssen B, Peters T, et al. Improvement in glucose metabolism after bariatric surgery: comparison of laparoscopic Roux-en-Y gastric bypass and laparoscopic sleeve gastrectomy: a prospective randomized trial. Ann Surg. 2009;250.

61. Reinehr T, Roth CL, Schernthaner GH, Kopp HP, Kriwanek S, Schernthaner G. Peptide YY and glucagon-like peptide-1 in morbidly obese patients before and after surgically induced weight loss. Obes Surg. 2007;17:1571-7.

62. Ye J., Hao Z., Mumphrey M.B. et al. GLP-1 receptor signaling is not required for reduced body weight after RYGB in rodents. $A m J$ Physiol Regul Integr Comp Physiol 2014

63. Cummings DE, Weigle DS, Frayo RS, et al. Plasma ghrelin levels after diet-induced weight loss or gastric bypass surgery. N Engl J Med. 2002;346:1623-30.

64. Foschi D, Corsi F, Colombo F, et al. Different effects of vertical banded gastroplasty and Roux-en-Y gastric bypass on meal inhibition of ghrelin secretion in morbidly obese patients. J Invest Surg. 2008;21:77-81.

65. Fruhbeck G, Rotellar F, Hernández-Lizoain JL, et al. Fasting plasma ghrelin concentrations 6 months after gastric bypass are not determined by weight loss or changes in insulinemia. Obes Surg. 2004; 14:1208-15.

66. Geloneze B, Tambascia MA, Pilla VF, Geloneze SR, Repetto EM, Pareja JC. Ghrelin: a gut-brain hormone: effect of gastric bypass surgery. Obes Surg. 2003;13:17-22.

67. Leonetti F, Silecchia G, Iacobellis G, et al. Different plasma ghrelin levels after laparoscopic gastric bypass and adjustable gastric banding in morbid obese subjects. J Clin Endocrinol Metab. 2003;88:4227-31.

68. Lin E, Gletsu N, Fugate K, et al. The effects of gastric surgery on systemic ghrelin levels in the morbidly obese. Arch Surg. 2004;139:780-4.

69. Morinigo R, Casamitjana R, Moize V, et al. Short-term effects of gastric bypass surgery on circulating ghrelin levels. Obes Res. 2004;12:1108-16.

70. Tritos NA, Mun E, Bertkau A, Grayson R, Maratos-Flier E, Goldfine A. Serum ghrelin levels in response to glucose load in obese subjects post-gastric bypass surgery. Obes Res. 2003;11: 919-24.

71. Couce M, Cottam D, Esplen J, Schauer P, Burguera B. Is ghrelin the culprit for weight loss after gastric bypass surgery? A negative answer. Obes Surg. 2006;16:870-8. 
72. Faraj M, Havel PJ, Phélis S, Blank D, Sniderman AD, Cianflone K. Plasma acylation-stimulating protein, adiponectin, leptin, and ghrelin before and after weight loss induced by gastric bypass surgery in morbidly obese subjects. J Clin Endocrinol Metab. 2003;88:1594-602.

73. Karamanakos SN, Vagenas K, Kalfarentzos F, Alexandrides TK. Weight loss, appetite suppression, and changes in fasting and postprandial ghrelin and peptide-YY levels after Roux-en-Y gastric bypass and sleeve gastrectomy: a prospective, double blind study. Ann Surg. 2008;247:401-7.

74. Korner J, Bessler M, Cirilo LJ, et al. Effects of Roux-en-Y gastric bypass surgery on fasting and postprandial concentrations of plasma ghrelin, peptide YY, and insulin. J Clin Endocrinol Metab. 2005;90:359-65.

75. Korner J, Inabnet W, Febres G, et al. Prospective study of gut hormone and metabolic changes after adjustable gastric banding and Roux-en-Y gastric bypass. Int $\mathrm{J}$ Obes (Lond). 2009;33:786-95.

76. Liou JM, Lin JT, Lee WJ, et al. The serial changes of ghrelin and leptin levels and their relations to weight loss after laparoscopic minigastric bypass surgery. Obes Surg. 2008;18:84-9.

77. Olivan B, Teixeira J, Bose M, et al. Effect of weight loss by diet or gastric bypass surgery on peptide YY3-36 levels. Ann Surg. 2009;249:948-53.

78. Stoeckli R, Chanda R, Langer I, Keller U. Changes of body weight and plasma ghrelin levels after gastric banding and gastric bypass. Obes Res. 2004;12:346-50.

79. Whitson BA, Leslie DB, Kellogg TA, et al. Entero-endocrine changes after gastric bypass in diabetic and nondiabetic patients: a preliminary study. J Surg Res. 2007;141:31-9.

80. Garcia-Fuentes E, Garrido-Sanchez L, Garcia-Almeida JM, et al. Different effect of laparoscopic Roux-en-Y gastric bypass and open biliopancreatic diversion of Scopinaro on serum PYY and ghrelin levels. Obes Surg. 2008;18:1424-9.

81. Holdstock C, Engström BE, Ohrvall M, Lind L, Sundbom M, Karlsson FA. Ghrelin and adipose tissue regulatory peptides: effect of gastric bypass surgery in obese humans. J Clin Endocrinol Metab. 2003;88:3177-83.

82. Sundbom M, Holdstock C, Engström BE, Karlsson FA. Early changes in ghrelin following Roux-en-Y gastric bypass: influence of vagal nerve functionality? Obes Surg. 2007;17:304-10.

83. Vendrell J, Broch M, Vilarrasa N, et al. Resistin, adiponectin, ghrelin, leptin, and proinflammatory cytokines: relationships in obesity. Obes Res. 2004;12:962-71.

84. Ybarra J, Bobbioni-Harsch E, Chassot G, et al. Persistent correlation of ghrelin plasma levels with body mass index both in stable weight conditions and during gastric-bypass-induced weight loss. Obes Surg. 2009;19:327-31.

85. Pournaras DJ, le Roux CW. Ghrelin and metabolic surgery. Int J Pept. 2010;2010:733-43.

86. Berthoud HR, Shin AC, Zheng H. Obesity surgery and gut-brain communication. Physiol Behav. 2011;105:106-19.

87. Berthoud HR. Vagal and hormonal gut-brain communication: from satiation to satisfaction. Neurogastroenterol Motil. 2008;20 Suppl 1:64-72.

88. Berthoud HR. The vagus nerve, food intake and obesity. Regul Pept. 2008;149:15-25.

89. Schwartz MW, Woods SC, Porte D, Seeley RJ, Baskin DG. Central nervous system control of food intake. Nature. 2000;404:661-71.

90. le Roux CW, Neary NM, Halsey TJ, et al. Ghrelin does not stimulate food intake in patients with surgical procedures involving vagotomy. J ClinEndocrinol Metabol. 2005;90:4521-4.

91. Ochner CN, Kwok Y, Conceicao E, et al. Selective reduction in neural responses to high calorie foods following gastric bypass surgery. Ann Surg. 2011;253:502-7.
92. Forman EM, Hoffman KL, McGrath KB, Herbert JD, Brandsma LL, Lowe MR. A comparison of acceptance- and control-based strategies for coping with food cravings: an analog study. Behav Res Ther. 2007;45:2372-86.

93. Lowe MR, van Steenburgh J, Ochner CN. Individual differences in brain activation in relation to ingestive behavior and obesity. Physiol Behav. 2009;5:561-71.

94. Lowe MR, Butryn ML, Didie ER, et al. The Power of Food Scale. A new measure of the psychological influence of the food environment. Appetite. 2009;53:114-8.

95. Kreymann B, Ghatei MA, Williams G, Bloom SR. Glucagon-like peptide-1 7-36: a physiological incretin in man. Lancet. 1987;330:1300-4.

96. Katsuma S, Hirasawa A, Tsujimoto G. Bile acids promote glucagon-like peptide-1 secretion through TGR5 in a murine enteroendocrine cell line STC-1. Biochem Biophys Res Commun. 2005;329:386-90.

97. Patti ME, Houten SM, Bianco AC, et al. Serum bile acids are higher in humans with prior gastric bypass: potential contribution to improved glucose and lipid metabolism. Obesity. 2009;17: 1671-7.

98. Watanabe M, Houten SM, Mataki C, et al. Bile acids induce energy expenditure by promoting intracellular thyroid hormone activation. Nature. 2006;439:484-9.

99. Ge H, Baribault H, Vonderfecht $\mathrm{S}$, et al. Characterization of a FGF19 variant with altered receptor specificity revealed a central role for FGFR1c in the regulation of glucose metabolism. PLoS One. 2012; 7:e33603.

100. Morton G.J., Kaiyala K.J., Foster-Schubert K.E., Cummings D.E., Schwartz M.W. Carbohydrate feeding dissociates the postprandial FGF19 response from circulating bile acid levels in humans. The Journal of Clinical Endocrinology \& Metabolism 2013

101. Holt JA, Luo G, Billin AN, et al. Definition of a novel growth factor-dependent signal cascade for the suppression of bile acid biosynthesis. Genes Dev. 2003;17:1581-91.

102. Inagaki $\mathrm{T}$, Choi M, Moschetta A, et al. Fibroblast growth factor 15 functions as an enterohepatic signal to regulate bile acid homeostasis. Cell Metab. 2005;2:217-25.

103. Roberts RE, Glicksman C, Alaghband-Zadeh J, Sherwood RA, Akuji N, le Roux CW. The relationship between postprandial bile acid concentration, GLP-1, PYY and ghrelin. Clin Endocrinol (Oxf). 2011;74:67-72.

104. Pournaras DJ, Glicksman C, Vincent RP, et al. The role of bile after Roux-en-Y gastric bypass in promoting weight loss and improving glycaemic control. Endocrinology. 2012;153:3613-9.

105. Furet JP, Kong LC, Tap J, et al. Differential adaptation of human gut microbiota to bariatric surgery-induced weight loss: links with metabolic and low-grade inflammation markers. Diabetes. 2010;59:3049-57.

106. Clarke SF, Murphy EF, Nilaweera K, et al. The gut microbiota and its relationship to diet and obesity: new insights. Gut Microbes. 2012;3:186-202.

107. Armougom F, Henry M, Vialettes B, Raccah D, Raoult D. Monitoring bacterial community of human gut microbiota reveals an increase in Lactobacillus in obese patients and methanogens in anorexic patients. PLoS One. 2009;4:e7125.

108. Ley RE, Turnbaugh PJ, Klein S, Gordon JI. Microbial ecology: human gut microbes associated with obesity. Nature. 2006;444: 1022-3.

109. Turnbaugh PJ, Hamady M, Yatsunenko T, et al. A core gut microbiome in obese and lean twins. Nature. 2009;457:480-4.

110. Turnbaugh PJ, Ley RE, Mahowald MA, Magrini V, Mardis ER, Gordon JI. An obesity-associated gut microbiome with increased capacity for energy harvest. Nature. 2006;444:1027-131. 
111. Zhang H, DiBaise JK, Zuccolo A, et al. Human gut microbiota in obesity and after gastric bypass. Proc Natl Acad Sci. 2009;106: 2365-70.

112. Aron-Wisnewsky J, Clement K. Gut microbiota in obesity and type-2 diabetes: links with diet and weight loss intervention. Intestin Microbiota Health Dis Mod Concepts. 2014;307.

113. Liou A.P., Paziuk M., Luevano J.M., Machineni S., Turnbaugh P.J., Kaplan L.M. Conserved shifts in the gut microbiota due to gastric bypass reduce host weight and adiposity. Sci Transl Med 2013; 5:178ra41.

114. Wurtman Judith J. The involvement of brain serotonin in excessive carbohydrate snacking by obese carbohydrate cravers. J Am Diet Assoc. 1984;84(9):1004-7.

115. Spitzer L, Rodin J. Human eating behavior: a critical review of studies in normal weight and overweight individuals. Appetite. 1981;2:293-329.

116. Drewnowski A, Brunzell JD, Sande K, Iverius PH, Greenwood MRC. Sweet tooth reconsidered: taste responsiveness in human obesity. Physiol Behav. 1985;35:617-22.

117. Rodin J, Radke-Sharpe N, Rebuffé-Scrive M, Greenwood MR. Weight cycling and fat distribution. Int J Obes. 1990;14:303-10.

118. Pangborn R, Simon M. Body size and sweetness preference. J Am Diet Assoc. 1958;34(9):924-8.

119. Lowe MR, Butryn ML. Hedonic hunger: a new dimension of appetite? Physiol Behav. 2007;91:432-9.

120. Schultes B, Ernst B, Wilms B, Thurnheer M, Hallschmid M. Hedonic hunger is increased in severely obese patients and is reduced after gastric bypass surgery. Am J Clin Nutr. 2010;92: 277-83.

121. Ernst B, Thurnheer M, Wilms B, Schultes B. Differential changes in dietary habits after gastric bypass versus gastric banding operations. Obes Surg. 2009;19:274-80.

122. Olbers T, Bjorkman S, Lindroos A, et al. Body composition, dietary intake, and energy expenditure after laparoscopic Roux-en-Y gastric bypass and laparoscopic vertical banded gastroplasty: a randomized clinical trial. Ann Surg. 2006;244:715-22.

123. Miras AD, Le Roux CW. Bariatric surgery and taste: novel mechanisms of weight loss. Curr Opin Gastroenterol. 2010;26(2):140-5.

124. Deitel M. The change in the dumping syndrome concept. Obes Surg. 2008;18:1622-4.

125. Thomas JR, Gizis F, Marcus E. Food selections of Roux-en-Y gastric bypass patients up to 2.5 years postsurgery. J Am Diet Assoc. 2010;110:608-12.

126. Laurenius A, Larsson I, Melanson KJ, et al. Decreased energy density and changes in food selection following Roux-en-Y gastric bypass. Eur J Clin Nutr. 2013;67:168-73.

127. Kenler HA, Brolin RE, Cody RP. Changes in eating behavior after horizontal gastroplasty and Roux-en-Y gastric bypass. Am J Clin Nutr. 1990;52:87-92.

128. Scholtz S., Miras A.D., Chhina N. et al. Obese patients after gastric bypass surgery have lower brain-hedonic responses to food than after gastric banding. Gut, gutjnl-2013 2013

129. Tam CS, Berthoud HR, Bueter M, et al. Could the mechanisms of bariatric surgery hold the key for novel therapies?: report from a Pennington Scientific Symposium. Obes Rev. 2011;12:984-94.

130. Meillon S, Miras AD, Roux CW. Gastric bypass surgery alters food preferences through changes in the perception of taste. Clinical Practice. 2013;10:471-9.

131. Sugerman HJ, Londrey GL, Kellum JM, et al. Weight loss with vertical banded gastroplasty and Roux-en-Y gastric bypass: selective vs. random assignment. Am J Surg. 1989;5:457-64.

132. Sugerman HJ, Starkey JV, Birkenhauer R. A randomized prospective trial of gastric bypass versus vertical banded gastroplasty for morbid obesity and their effects on sweets versus non-sweets eaters. Ann Surg. 1987;205:613-24.
133. Linner JH. Comparative effectiveness of gastric bypass and gastroplasty: a clinical study. Arch Surg. 1982;117:695-700.

134. Hofmann B, Hjelmesaeth J, Sovik TT. Moral challenges with surgical treatment of type 2 diabetes. J Diabetes Complicat. 2013;27: 597-603.

135. Schafe G.E., Bernstein I.L. Taste aversion learning. 1996

136. Garcia J, Koelling RA. Relation of cue to consequence in avoidance learning. Psychon Sci. 1966;4:123-4.

137. Birch LL. Development of food preferences. Annu Rev Nutr. 1999;19:41-62.

138. Spector AC, Glendinning JI. Linking peripheral taste processes to behavior. Curr Opin Neurobiol. 2009;19:370-7.

139. Spector AC. Linking gustatory neurobiology to behavior in vertebrates. Neurosci Biobehav Rev. 2000;24:391-416.

140. Le Roux CW, Bueter M, Theis N, et al. Gastric bypass reduces fat intake and preference. Am J Physiol Regul Integr Comp Physiol. 2011;301(4):R1057-66.

141. Bueter M, Miras AD, Chichger H, et al. Alterations of sucrose preference after Roux-en-Y gastric bypass. Physiol Behav. 2011;104:709-21.

142. Hajnal A, Kovacs P, Ahmed T, Meirelles K, Lynch CJ, Cooney $\mathrm{RN}$. Gastric bypass surgery alters behavioral and neural taste functions for sweet taste in obese rats. Am J Physiol Gastrointest Liver Physiol. 2010;299:G967-79.

143. Shin AC, Zheng H, Pistell PJ, Berthoud HR. Roux-en-Y gastric bypass surgery changes food reward in rats. Int J Obes. 2011;35: 642-51.

144. Tichansky D, Rebecca GA, Madan A, Harper J, Tokita K, Boughter J. Decrease in sweet taste in rats after gastric bypass surgery. Surg Endosc. 2011;25:1176-81.

145. Miras AD, Jackson RN, Goldstone AP, Olbers T, Hackenberg T, Spector AC, et al. Gastric bypass surgery for obesity decreases the reward value of a sweet-fat stimulus as assessed in a progressive ratio task. Am J Clin Nutr. 2012;96(3):467-73. Ref Type: Journal (Full).

146. Nestoridi E, Kvas S, Kucharczyk J, Stylopoulos N. Resting energy expenditure and energetic cost of feeding are augmented after Roux-en-Y gastric bypass in obese mice. Endocrinology. 2012;153:2234-44.

147. Carrasco F, Papapietro K, Csendes A, et al. Changes in resting energy expenditure and body composition after weight loss following Roux-en-Y gastric bypass. Obes Surg. 2007;17:608-16.

148. Flancbaum L, Verducci J, Choban P. Changes in measured resting energy expenditure after Roux-en-Y gastric bypass for clinically severe obesity are not related to bypass limb-length. Obes Surg. 1998;8:437-43.

149. Faria S, Kelly E, Faria O. Energy expenditure and weight regain in patients submitted to Roux-en-Y gastric bypass. Obes Surg. 2009;19:856-9.

150. Carrasco F, Rojas P, Ruz M, et al. Energy expenditure and body composition in severe and morbid obese women after gastric bypass]. Revista m Ñdica de Chile. 2008;136:570.

151. Adami GF, Campostano A, Bessarione D, et al. Resting energy expenditure in long-term postobese subjects after weight normalization by dieting or biliopancreatic diversion. Obes Surg. 1993;3: 397-9.

152. Castro CM, Lima MM, Rasera Jr I, Oliveira Jr A, Gomes GP, Aparecida CG. Effects of Roux-en-Y gastric bypass on resting energy expenditure in women. Obes Surg. 2008;18:1376-80.

153. Adami GF, Campostano A, Gandolfo P, Marinari G, Bessarione D, Scopinaro N. Body composition and energy expenditure in obese patients prior to and following biliopancreatic diversion for obesity. Eur Surg Res. 1996;28:295-8.

154. Saeidi N, Meoli L, Nestoridi E, et al. Reprogramming of intestinal glucose metabolism and glycemic control in rats after gastric bypass. Science. 2013;341:406-10. 
155. Bobbioni-Harsch E, Morel P, Huber O, et al. Energy economy hampers body weight loss after gastric bypass. J Clin Endocrinol Metab. 2000;85:4695-700.

156. Carey D, Pliego G, Raymond R. Body composition and metabolic changes following bariatric surgery: effects on fat mass, lean mass and basal metabolic rate: six months to one-year follow-up. Obes Surg. 2006;16:1602-8.

157. Das SK, Roberts SB, Kehayias JJ, et al. Body composition assessment in extreme obesity and after massive weight loss induced by gastric bypass surgery. Am J Physiol Endocrinol Metab. 2003;284:E1080-8.

158. Metcalf B, Rabkin R, Rabkin J, Metcalf L, Lehman-Becker L. Weight loss composition: the effects of exercise following obesity surgery as measured by bioelectrical impedance analysis. Obes Surg. 2005;15:183-6.

159. O'Brien PE. Bariatric surgery: mechanisms, indications and outcomes. J Gastroenterol Hepatol. 2010;25:1358-65.

160. Kumar R, Lieske JC, Collazo-Clavell ML, et al. Fat malabsorption and increased intestinal oxalate absorption are common after Roux-en-Y gastric bypass surgery. Surgery. 2011;149:654-61.

161. Odstrcil EA, Martinez JG, Santa Ana CA, et al. The contribution of malabsorption to the reduction in net energy absorption after longlimb Roux-en-Y gastric bypass. Am J Clin Nutr. 2010;92:704-13.

162. Carswell KA, Vincent RP, Belgaumkar AP, et al. The effect of bariatric surgery on intestinal absorption and transit time. Obes Surg. 2014;1-10(5):796-805. 1-10.

163. Santry HP, Gillen DL, Lauderdale DS. Trends in bariatric surgical procedures. JAMA. 2005;294:1909-17.

164. National Bariatric Surgery Registry, First Registry Report to march 2010. 2010. Ref Type: Report

165. Tack J, Arts J, Caenepeel P, De Wulf D, Bisschops R. Pathophysiology, diagnosis and management of postoperative dumping syndrome. Nat Rev Gastroenterol Hepatol. 2009;6: 583-90.

166. Ukleja A. Dumping syndrome: pathophysiology and treatment. Nutr Clin Pract. 2005;20:517-25.

167. Mathews DH. Change in effective circulating volume during experimental dumping syndrome. Surgery. 1960;48(1):185-94.

168. Cummings DE, Foster-Schubert KE, Overduin J. Ghrelin and energy balance: focus on current controversies. Curr Drug Targets. 2005;6:153-69.

169. Kapoor RR, James C, Hussain K. Advances in the diagnosis and management of hyperinsulinemic hypoglycemia. Nat Clin Pract End Met. 2009;5:101-12.

170. Service GJ, Thompson GB, Service FJ, Andrews JC, CollazoClavell ML, Lloyd RV. Hyperinsulinemic hypoglycemia with nesidioblastosis after gastric-bypass surgery. N Engl J Med. 2005;353:249-54.

171. Patti ME, Goldfine AB. Hypoglycemia after gastric bypass: the dark side of GLP-1. Gastroenterology. 2014;146:605-8.

172. Comeau E, Gagner M, Inabnet WB, Herron DM, Quinn TM, Pomp A. Symptomatic internal hernias after laparoscopic bariatric surgery. Surg Endosc. 2005;19:34-9.

173. Husain S, Ahmed AR, Johnson J, Boss T, O'Malley W. Smallbowel obstruction after laparoscopic Roux-en-Y gastric bypass: etiology, diagnosis, and management. Arch Surg. 2007;142:988.

174. Garza Jr E, Kuhn J, Arnold D, Nicholson W, Reddy S, McCarty T. Internal hernias after laparoscopic Roux-en-Y gastric bypass. Am J Surg. 2004;188:796-800.

175. Cho M, Carrodeguas L, Pinto D, et al. Diagnosis and management of partial small bowel obstruction after laparoscopic antecolic antegastric Roux-en-Y gastric bypass for morbid obesity. J Am Coll Surg. 2006;202:262-8

176. Filip JE, Mattar SG, Bowers SP, Smith CD. Internal hernia formation after laparoscopic Roux-en-Y gastric bypass for morbid obesity. Am Surg. 2002;68:640-3.
177. Martin LC, Merkle EM, Thompson WM. Review of internal hernias: radiographic and clinical findings. Am J Roentgenol. 2006;186:703-17.

178. Reddy SA, Yang C, McGinnis LA, Seggerman RE, Garza E, Ford III KL. Diagnosis of transmesocolic internal hernia as a complication of retrocolic gastric bypass: CT imaging criteria. Am J Roentgenol. 2007;189:52-5.

179. Swartz D.E., Gonzalez V., Felix E.L. Anastomotic stenosis after Roux-en-Y gastric bypass: a rational approach to treatment. Surgery for Obesity and Related Diseases 2:632-636

180. Halverson JD. Micronutrient deficiencies after gastric bypass for morbid obesity. Am Surg. 1986;52(11):594-8.

181. Smith CD, Herkes SB, Behrns KE, et al. Gastric acid secretion and vitamin B12 absorption after vertical Roux-gastric-Y bypass for morbid obesity. Ann Surg. 1993;218:91-6.

182. Decker GA, Swain JM, Crowell MD, Scolapio JS. Gastrointestinal and nutritional complications after bariatric surgery. Am J Gastroenterol. 2007;102:2571-80.

183. Balsiger, Bruno M., Kennedy, Frank P., Abu-Lebdeh, Haitham S., Collazo-Clavell, Maria, Jensen, Michael D., O'Brien, Timothy, Hensrud, Donald D., Dinneen, Sean F., Thompson, Geoffrey B., and Que, Florencia G. Prospective evaluation of Roux-en-Y gastric bypass as primary operation for medically complicated obesity. Mayo Clinic Proceedings 75[7], 673-680. 2000. Elsevier. Ref Type: Conference Proceeding

184. Avinoah E, Ovnat A, Charuzi I. Nutritional status seven years after Roux-en-Y gastric bypass surgery. Surgery. 1992;111:137-42.

185. Rhode BM, Arseneau P, Cooper BA, Katz M, Gilfix BM, MacLean LD. Vitamin B-12 deficiency after gastric surgery for obesity. Am J Clin Nutr. 1996;63:103-9.

186. Brolin RE, Gorman JH, Petschenik AJ, Bradley LJ, Kenler HA, Cody RP. Are vitamin B12 and folate deficiency clinically important after roux-en-Y gastric bypass? J Gastrointest Surg. 1998;2: 436-42.

187. Updegraff TA, Neufeld NJ. Protein, iron, and folate status of patients prior to and following surgery for morbid obesity. J Am Diet Assoc. 1981;78:135.

188. Brolin RE, LaMarca LB, Kenler HA, Cody RP. Malabsorptive gastric bypass in patients with superobesity. J Gastrointest Surg. 2002;6:195-205.

189. Wortsman J, Matsuoka LY, Chen TC, Lu Z, Holick MF. Decreased bioavailability of vitamin D in obesity. Am J Clin Nutr. 2000;72: 690-3.

190. Coates PS, Fernstrom JD, Fernstrom MH, Schauer PR, Greenspan SL. Gastric bypass surgery for morbid obesity leads to an increase in bone turnover and a decrease in bone mass. J Clin Endocrinol Metabol. 2004;89:1061-5.

191. von Mach MA, Stoeckli R, Bilz S, Kraenzlin M, Langer I, Keller U. Changes in bone mineral content after surgical treatment of morbid obesity. Metabolism. 2004;53:918-21.

192. Shah M, Simha V, Garg A. Long-term impact of bariatric surgery on body weight, comorbidities, and nutritional status. J Clin Endocrinol Metabol. 2006;91:4223-31.

193. Abegg K, Gehring N, Wagner CA, et al. Roux-en-Y gastric bypass surgery reduces bone mineral density and induces metabolic acidosis in rats. Am J Physiol Regul Integr Comp Physiol. 2013;305: R999-R1009.

194. Lalmohamed A, de Vries F, Bazelier MT, et al. Risk of fracture after bariatric surgery in the United Kingdom: population based, retrospective cohort study. BMJ: Br Med J . 2012;345.

195. Langlois JA, Mussolino ME, Visser M, Looker AC, Harris T, Madans J. Weight loss from maximum body weight among middle-age and older white women and the risk of hip fracture: the NHANES I epidemiologic follow-up study. Osteoporos Int. 2011;12:763-8. 
196. Reid IR. Relationships between fat and bone. Osteoporos Int. 2008;19:595-606.

197. Reid IR. Relationships among body mass, its components, and bone. IBMS BoneKEy. 2002.

198. Asplin JR, Coe FL. Hyperoxaluria in kidney stone formers treated with modern bariatric surgery. J Urol. 2007;177:565-9.

199. Duffey BG, Pedro RN, Makhlouf A, et al. Roux-en-Y gastric bypass is associated with early increased risk factors for development of calcium oxalate nephrolithiasis. J Am Coll Surg. 2008;206:1145-53.

200. Sinha MK, Collazo-Clavell ML, Rule A, et al. Hyperoxaluric nephrolithiasis is a complication of Roux-en-Y gastric bypass surgery. Kidney Int. 2007;72:100-7.

201. Mole DR, Tomson CRV, Mortensen N, Winearls CG. Renal complications of jejuno-ileal bypass for obesity. QJM. 2001;94:69-77.
202. Matlaga BR, Shore AD, Magnuson T, Clark JM, Johns R, Makary MA. Effect of gastric bypass surgery on kidney stone disease. J Urol. 2009;181:2573-7.

203. Pinkney J. Consensus at last? The International Diabetes Federation statement on bariatric surgery in the treatment of obese type 2 diabetes. Diabet Med. 2011;28:884-5.

204. Cummings D.E. Endocrine mechanisms mediating remission of diabetes after gastric bypass surgery. Int $J$ Obes $0 \mathrm{AD}$; 33:S33-S40.

205. Fruhbeck G. Bariatric and metabolic surgery: a shift in eligibility and success criteria. Nat Rev Endocrinol. 2015.

206. Shin AC, Zheng H, Berthoud HR. Vagal innervation of the hepatic portal vein and liver is not necessary for Roux-en-Y gastric bypass surgery-induced hypophagia, weight loss, and hypermetabolism. Ann Surg. 2012;255:294-301. 